\title{
Ternary erbium chromium sulfides : structural relationships and magnetic properties
}

Article

Accepted Version

Vaqueiro, P., Szkoda, I., Sanchez, R. D. and Powell, A. V. (2009) Ternary erbium chromium sulfides : structural relationships and magnetic properties. Inorganic Chemistry, 48 (4). pp. 1284-1292. ISSN 0020-1669 doi:

https://doi.org/10.1021/ic801482a Available at https://centaur.reading.ac.uk/32494/

It is advisable to refer to the publisher's version if you intend to cite from the work. See Guidance on citing.

To link to this article DOI: http://dx.doi.org/10.1021/ic801482a

Publisher: American Chemical Society

All outputs in CentAUR are protected by Intellectual Property Rights law, including copyright law. Copyright and IPR is retained by the creators or other copyright holders. Terms and conditions for use of this material are defined in the End User Agreement.

www.reading.ac.uk/centaur 
Central Archive at the University of Reading

Reading's research outputs online 


\title{
Ternary Erbium Chromium Sulphides: Structural Relationships and Magnetic Properties
}

\author{
Paz Vaqueiro, ${ }^{\mathrm{a}}$ Iwona Szkoda, ${ }^{\mathrm{a}}$ Rodolfo D. Sanchez ${ }^{\mathrm{b}}$ and \\ Anthony V. Powell ${ }^{\mathrm{a}}$ \\ ${ }^{a}$ Department of Chemistry, Heriot-Watt University, \\ Edinburgh EH14 4AS, UK \\ ${ }^{\mathrm{b}}$ Centro Atomico Bariloche, 8400 Bariloche (RN), Argentina
}

Correspondence to:

Prof. A.V. Powell

Department of Chemistry

Heriot-Watt University

Edinburgh EH14 4AS

UK

Fax: +44 (0)1314513180

E-mail: a.v.powell@hw.ac.uk 


\begin{abstract}
Single crystals of four erbium-chromium sulphides have been grown by chemical vapour transport using iodine as the transporting agent. Single-crystal X-ray diffraction reveals that in $\mathrm{Er}_{3} \mathrm{CrS}_{6}$, octahedral sites are occupied exclusively by $\mathrm{Cr}^{3+}$ cations, leading to one-dimensional $\mathrm{CrS}_{4}{ }^{5-}$ chains of edge-sharing octahedra, whilst in $\mathrm{Er}_{2} \mathrm{CrS}_{4}, \mathrm{Er}^{3+}$ and $\mathrm{Cr}^{2+}$ cations occupy the available octahedral sites in an ordered manner. By contrast, in $\mathrm{Er}_{6} \mathrm{Cr}_{2} \mathrm{~S}_{11}$ and $\mathrm{Er}_{4} \mathrm{CrS}_{7}, \mathrm{Er}^{3+}$ and $\mathrm{Cr}^{2+}$ ions are disordered over the octahedral sites. In $\mathrm{Er}_{2} \mathrm{CrS}_{4}, \mathrm{Er}_{6} \mathrm{Cr}_{2} \mathrm{~S}_{11}$ and $\mathrm{Er}_{4} \mathrm{CrS}_{7}$, the network of octahedra generates an anionic framework constructed from $\mathrm{M}_{2} \mathrm{~S}_{5}$ slabs of varying thickness, linked by one-dimensional octahedral chains. This suggests that these three phases belong to a series in which the anionic framework may be described by the general formula $\left[\mathrm{M}_{2 \mathrm{n}+1} \mathrm{~S}_{4 \mathrm{n}+3}\right]^{\mathrm{x}-}$, with charge balancing provided by $\mathrm{Er}^{3+}$ cations located in sites of high-coordination number within one-dimensional channels defined by the framework. $\mathrm{Er}_{4} \mathrm{CrS}_{7}, \mathrm{Er}_{6} \mathrm{Cr}_{2} \mathrm{~S}_{11}$ and $\mathrm{Er}_{2} \mathrm{CrS}_{4}$ may thus be considered as the $\mathrm{n}=1,2$ and $\infty$ members of this series. Whilst $\mathrm{Er}_{4} \mathrm{CrS}_{7}$ is paramagnetic, successive magnetic transitions associated with ordering of the chromium and erbium sub-lattices are observed on cooling $\mathrm{Er}_{3} \mathrm{CrS}_{6}\left(\mathrm{~T}_{\mathrm{C}}(\mathrm{Cr})=30 \mathrm{~K} ; \mathrm{T}_{\mathrm{C}}(\mathrm{Er})=11 \mathrm{~K}\right)$ and $\mathrm{Er}_{2} \mathrm{CrS}_{4}\left(\mathrm{~T}_{\mathrm{N}}(\mathrm{Cr})=\right.$ $\left.42 \mathrm{~K}, \mathrm{~T}_{\mathrm{N}}(\mathrm{Er})=10 \mathrm{~K}\right)$ whereas $\mathrm{Er}_{6} \mathrm{Cr}_{2} \mathrm{~S}_{11}$ exhibits ordering of the chromium sub-lattice only $\left(\mathrm{T}_{\mathrm{N}}=11.4 \mathrm{~K}\right)$.
\end{abstract}




\section{Introduction}

Mixed-metal chalcogenides containing transition-series elements, either exclusively or in conjunction with a diamagnetic main-group cation have been extensively studied for their structural, magnetic and electronic properties. ${ }^{1,2}$ In contrast, chalcogenides containing a transition-series element in conjunction with a rare-earth cation represent something of an under-developed area in solid-state chemistry. The high and variable coordination number of a rare-earth cation, offers a degree of structural complexity that goes beyond that in materials containing main-group or transition-metal ions with well-defined coordination preferences. Furthermore, the presence of $d$ - and $f$-block elements allows three types of electron-electron interaction, $d-d, d-f$ and $f-f$, to be simultaneously present affording the potential for a corresponding richness in the magnetic and transport properties.

The comparatively small number of examples of rare-earth transition-metal chalcogenides reported to date is dominated by the sulphides, with considerably fewer examples of selenides and only a handful of tellurides known. ${ }^{3}$ Moreover, even for the simplest ternary sulphides, systematic studies for a given stoichiometry of the structure and physical properties as a function of the rare-earth and/or transition-metal cation remain to be performed. For example, whilst the synthesis and lattice parameters of the series of phases $\mathrm{Ln}_{3} \mathrm{CrS}_{6}(\mathrm{Ln}=\mathrm{La}-\mathrm{Lu})^{4}$ have been reported, crystal structures have not been determined and little is known about their physical properties.

In many cases, structure has been inferred solely from comparison of powder X-ray diffraction data with those of known phases and detailed structural investigations, including the nature of any cation ordering have not been carried out. For example, single crystal X-ray diffraction data obtained for $\mathrm{Y}_{4} \mathrm{FeS}_{7}$ and $\mathrm{Ho}_{4} \mathrm{FeS}_{7}$ indicate a $\mathrm{Y}_{5} \mathrm{~S}_{7^{-}}$ 
type structure ${ }^{5,6}$ and, on the basis of powder X-ray diffraction data, it was suggested that other materials of general formula $\mathrm{Ln}_{4} \mathrm{MS}_{7}(\mathrm{Ln}=\mathrm{Y}, \mathrm{Dy}, \mathrm{Ho}, \mathrm{Er}, \mathrm{Tm}, \mathrm{Yb} ; \mathrm{M}=$ $\mathrm{Mg}, \mathrm{Cr}, \mathrm{Mn}, \mathrm{Fe}, \mathrm{Cd}$ ) are isostructural. However, it appears that related materials, initially formulated $\mathrm{Ln}_{4} \mathrm{MS}_{7}(\mathrm{M}=\mathrm{Mn}, \mathrm{Fe}, \mathrm{Co}, \mathrm{Ni} ; \mathrm{Ln}=\mathrm{La}, \mathrm{Ce}, \mathrm{Pr}$ and $\mathrm{Nd}),{ }^{7}$ are more complex than originally proposed since analysis of single-crystal X-ray diffraction data for " $\mathrm{Ce}_{4} \mathrm{FeS}_{7}$ " reveals a different structure and a crystallographically-determined composition $\mathrm{Ce}_{3} \mathrm{Fe}_{1.94} \mathrm{~S}_{7 .}{ }^{8}$

On the basis of powder X-ray diffraction data, three different structure types have been proposed for materials of general formula, $\mathrm{Ln}_{2} \mathrm{MS}_{4}(\mathrm{M}=\mathrm{Mg}, \mathrm{Cr}, \mathrm{Mn}, \mathrm{Fe})$, depending on the identity of the rare-earth cation. ${ }^{9}$ For the early lanthanides ( $\mathrm{Ln}=\mathrm{La}$ Gd), an orthorhombic phase was identified, while rare-earth ions drawn from later in the series $(\mathrm{Tb}-\mathrm{Tm})$ generally favour adoption of a $\mathrm{Y}_{2} \mathrm{MnS}_{4}$-type structure and a spineltype structure is also observed for Yb-containing phases. However, recent singlecrystal X-ray diffraction studies indicate greater complexity and reveal that the phases of nominal stoichiometry " $\mathrm{La}_{2} \mathrm{CrS}_{4}$ " and " $\mathrm{La}_{2} \mathrm{FeS}_{4}$ " are rhombohedral and better formulated $\mathrm{La}_{15.9} \mathrm{Cr}_{5.4} \mathrm{~S}_{32}{ }^{10}$ and $\mathrm{La}_{52} \mathrm{Fe}_{12} \mathrm{~S}_{90}{ }^{11}$ respectively. Single-crystal X-ray diffraction studies of $\mathrm{Y}_{2} \mathrm{MnS}_{4}$-type materials are confined to " $\mathrm{Yb}_{2} \mathrm{MnS}_{4}$ "12 and $\mathrm{Er}_{2} \mathrm{CrS}_{4},{ }^{13}$. In the former this led to its reformulation as $\mathrm{Yb}_{2.33} \mathrm{Mn}_{0.67} \mathrm{~S}_{4}$, whilst an enlarged unit cell was observed in the latter. Examination by electron microscopy of materials within the $\mathrm{MnS}-\mathrm{Er}_{2} \mathrm{~S}_{3}{ }^{14}$ system has confirmed the existence of $\mathrm{Y}_{2} \mathrm{MnS}_{4}$-type and $\mathrm{Y}_{5} \mathrm{~S}_{7}$-type phases, and suggested that other phases with intermediate compositions such as $\operatorname{Er}_{6} \mathrm{Mn}_{2} \mathrm{~S}_{11}$ and $\mathrm{Er}_{8} \mathrm{Mn}_{3} \mathrm{~S}_{15}$ may exist. Whilst a number of rare-earth transitionmetal sulphides of general formula $\mathrm{Ln}_{6} \mathrm{M}_{2} \mathrm{~S}_{11}$ have been reported, ${ }^{14,15}$ detailed structural analysis has been performed only for $\mathrm{Yb}_{6} \mathrm{Fe}_{2} \mathrm{~S}_{11}{ }^{16}$ and $\mathrm{Er}_{6} \mathrm{Cr}_{2} \mathrm{~S}_{11}{ }^{17}$ 
In this work we have sought to carry out a systematic study of the structural and magnetic properties of ternary erbium-chromium sulphides. The presence, or otherwise, of long-range magnetic order at low temperatures is correlated with the detailed structures determined by single-crystal X-ray diffraction. Moreover the identification of a common building block leads us to propose that these materials be considered the first members of a homologous series of compounds.

\section{Experimental}

Bulk powdered samples of all materials were prepared from mixtures of high-purity erbium (Sigma-Aldrich, 99.9\%), chromium (Alfa Aesar, 99.95\%) and sulphur (Sigma Aldrich, 99.99\%) powders of appropriate stoichiometry. The elements were ground in an agate mortar inside an argon-filled glovebox prior to sealing into evacuated $\left(<10^{-4}\right.$ Torr) silica tubes, together with $10 \mathrm{mg}$ of iodine. $\mathrm{Er}_{3} \mathrm{CrS}_{6}, \mathrm{Er}_{4} \mathrm{CrS}_{7}$ and $\mathrm{Er}_{6} \mathrm{Cr}_{2} \mathrm{~S}_{11}$ were prepared by heating the reaction mixtures at $1273 \mathrm{~K}$ for 1 week, whereas synthesis of $\mathrm{Er}_{2} \mathrm{CrS}_{4}$ required 2 weeks at this temperature. All products were cooled to room temperature at the natural rate of the furnace $\left(c a .5 \mathrm{~K} \mathrm{~min}^{-1}\right)$.

Single crystals of the four ternary sulphides were grown by chemical vapour transport from stoichiometric mixtures of the elements, using iodine $\left(3-5 \mathrm{mg} \mathrm{cm}^{-3}\right)$ as the transporting agent. The charge and growth zones were held at $1273 \mathrm{~K}$ and $1223 \mathrm{~K}$ respectively for the growth of $\mathrm{Er}_{3} \mathrm{CrS}_{6}$ and $\mathrm{Er}_{6} \mathrm{Cr}_{2} \mathrm{~S}_{11}$ crystals, whilst a steeper gradient $(1273 \mathrm{~K}$ to $1173 \mathrm{~K})$ was required for the formation of single crystals of $\mathrm{Er}_{2} \mathrm{CrS}_{4}$ and $\mathrm{Er}_{4} \mathrm{CrS}_{7}$. In all cases crystals suitable for structure determination by single-crystal $\mathrm{X}$ ray diffraction were obtained in 7 days.

Powder X-ray diffraction data for bulk samples were obtained using a Bruker D8 Advance powder diffractometer, operating with germanium-monochromated $\mathrm{CuK}_{\alpha 1}$ 
radiation $(\lambda=1.5405 \AA)$ and fitted with a Bruker LynxEye linear detector. Data were collected over the angular range $10 \leq 2 \theta /^{\circ} \leq 120$ in $0.014^{\circ}$ angular increments, counting for $2.4 \mathrm{~s}$ at each step. Magnetic measurements over the temperature range 90 $\leq \mathrm{T} / \mathrm{K} \leq 300$ were performed using a LakeShore 7300 series vibrating-sample magnetometer (VSM). Samples were contained in Lucite ${ }^{\circledR}$ capsules and measurements were conducted in an applied field of 1000G, after cooling in zero applied field ( $\mathrm{zfc}$ ). Measurements were extended to lower temperatures $(5 \leq \mathrm{T} / \mathrm{K} \leq 150)$ using a Quantum Design MPMS-5S SQUID susceptometer. Samples were loaded into gelatin capsules at room temperature and data were collected in a measuring field of $1000 \mathrm{G}$ after cooling under zfc conditions. In cases where magnetic transitions were identified, low-temperature magnetic susceptibilities were also measured after cooling in the applied field. Magnetization data as a function of field were collected in the range $0 \leq$ $\mathrm{H} / \mathrm{G} \leq 10000$. Data were corrected for the diamagnetism of the gelatin capsule and for intrinsic core diamagnetism.

Single crystals were mounted on glass fibres and X-ray intensity data collected using a Bruker X8 APEX 2 diffractometer ${ }^{18}$ with graphite monochromated Mo $\mathrm{K}_{\alpha}$ radiation $(\lambda=0.71073 \AA)$. Full crystallographic details are given in Table 1 . The structures were solved by direct methods using the program SIR92. ${ }^{19}$ Subsequent Fourier calculations and least-squares refinements on $F$ were carried out in the CRYSTALS program suite. $^{20}$ A Chebyshev polynomial was applied as a weighting scheme. ${ }^{21}$ Refined parameters are presented in Tables $2-5$ and selected bond distances are provided as supporting information.

\section{Results}

Structural Investigations 
The asymmetric unit of $\mathrm{Er}_{3} \mathrm{CrS}_{6}$ contains two and three crystallographically-distinct chromium and erbium ions respectively. Both chromium ions are trivalent and exhibit a slightly distorted octahedral coordination, with an average Cr-S distance of $2.44 \AA$. In contrast, two different coordination environments may be identified for the rareearth cations. $\operatorname{Er}(1)$ and $\operatorname{Er}(3)$ are surrounded by eight sulphur atoms in a bicapped trigonal-prismatic coordination, whilst $\operatorname{Er}(2)$ is seven coordinate and adopts a capped pseudo-octahedral arrangement. The average Er-S distances, which increase with increasing coordination number, are similar to those in the binary sulphide, $\mathrm{Er}_{2} \mathrm{~S}_{3}$, ${ }^{22}$ in which $\mathrm{Er}^{3+}$ cations exhibit coordination numbers in the range six to eight.

Single-crystal X-ray diffraction data for $\mathrm{Er}_{2} \mathrm{CrS}_{4}$ were initially indexed in the centrosymmetric space group Pbca. However, detailed examination of these data revealed a number of weak $(0 \mathrm{kl})$ reflections which violate the $k=2 n$ condition of the $b$ glide plane. The structure was subsequently solved in the non-centrosymmetric space group $P 2{ }_{1} c a$, as previously proposed by Tomas et al. ${ }^{13}$ With the exception of $\mathrm{S}(11)$ and $S(12)$, the structure exhibits pseudosymmetry, and therefore similarity restraints were applied to the anisotropic thermal parameters during the least-squares refinements.

There are two crystallographically-distinct chromium and four erbium ions in the asymmetric unit of $\mathrm{Er}_{2} \mathrm{CrS}_{4}$. All chromium ions exhibit a distorted octahedral coordination, with two long and four short Cr-S distances, of ca. 2.84 and $2.48 \AA$ respectively. This appears to be a rare example of a static Jahn-Teller distortion associated with the degenerate ground state of the $\mathrm{Cr}^{2+}: \mathrm{d}^{4}$ ion, whose presence is required by formal valence considerations and supported by bond valence ${ }^{23}$ sums. Although Jahn-Teller distortions of $\mathrm{Cr}^{2+}$ have been reported in halides such as $\mathrm{Rb}_{2} \mathrm{CrCl}_{4}$ and $\mathrm{ACrCl}_{3}(\mathrm{~A}=\mathrm{Cs}, \mathrm{Rb}),{ }^{24,25}$ the binary phase $\mathrm{CrS}$, represents one of the 
few previously characterised examples of such a distortion in a sulphide. ${ }^{26}$ The erbium ions exhibit two different coordination environments, octahedral and monocapped trigonal prismatic, with average Er-S bond lengths of $c a \cdot 2.67 \AA$ and $c a \cdot 2.82 \AA$ respectively.

$\mathrm{Er}_{6} \mathrm{Cr}_{2} \mathrm{~S}_{11}$ has been reported to crystallise in the non-centrosymmetric space group $B b 2{ }_{1} m$, an alternative setting of $C m c{ }_{1} \cdot{ }^{17}$ However, application of Platon/Addsym ${ }^{27,28}$ in order to identify missing symmetry elements indicates that there is an additional mirror plane, and that the structure is more correctly described in the centrosymmetric space group Cmcm. Refinements using single-crystal data were therefore carried out in $\mathrm{Cmcm}$, and resulted in a low weighted residual of $2.35 \%$ (Table 1). The asymmetric unit contains three crystallographically-independent cation sites of octahedral coordination, together with two erbium sites of distorted trigonal prismatic and monocapped trigonal prismatic coordination. The $\mathrm{Cr}^{2+}$ and $\mathrm{Er}^{3+}$ cations are disordered over the three octahedral sites. The average metal-sulphur distance at the octahedral sites is $c a ., 2.65 \AA$ which is slightly larger than that observed for divalent chromium in $\mathrm{Er}_{2} \mathrm{CrS}_{4}$, and is consistent with the presence of both chromium and the larger erbium cations at these sites.

There are three crystallographically-independent cation sites in $\mathrm{Er}_{4} \mathrm{CrS}_{7}$, two of which are octahedrally coordinated by sulphur whilst the third is a seven-coordinate monocapped trigonal-prismatic site. Structural refinement using single-crystal X-ray diffraction data reveal that erbium and chromium ions are disordered over both octahedral sites, with the remaining erbium ions occupying the seven-coordinate site. The average cation-sulphur distances at the octahedral sites is $c a .2 .66 \AA$. The average Er-S distance at the seven-coordinated site is $c a .2 .82 \AA$, comparable to those found in the structures of $\mathrm{Er}_{2} \mathrm{CrS}_{4}$ and $\mathrm{Er}_{3} \mathrm{CrS}_{6}$. During initial structural refinements, the anion 
$\mathrm{S}(7)$ was located at a $2(d)(0.5,0,0.5)$ site. This resulted in large oblate anisotropic thermal parameters, suggesting that this ion might be disordered. In subsequent refinements $\mathrm{S}(7)$ was placed at a $4(i)$ site (0.4861(4), 0, 0.4814(4)), with a site occupancy factor of 0.5. Similar disorder has previously been reported for the isostructural $\operatorname{Tm}_{5} \mathrm{~S}_{7 .}{ }^{29}$

Powder X-ray diffraction data for bulk samples prepared by high-temperature synthesis are consistent with the formation of single phase products. The data can be indexed on the basis of the unit-cells determined by single-crystal X-ray diffraction, with refined parameters that are in good agreement with those obtained in the singlecrystal study (Table 6).

\section{Magnetic Properties}

Magnetic susceptibility data (Figure 1) reveal that all materials follow Curie-Weiss behaviour at high temperatures. The effective magnetic moments, $\mu_{\mathrm{eff}}$, (Table 7) derived from the fit of a Curie-Weiss expression to the data obtained by the VSM technique are in good agreement with expectations based on spin-only behaviour for the chromium cations and a free-ion value of $9.58 \mu_{\mathrm{B}}$, calculated from the Landé formula, for the $\mu_{\text {eff }}$ of the $\mathrm{Er}^{3+}$ cations. $\mathrm{Er}_{4} \mathrm{CrS}_{7}$ exhibits a small negative Weiss constant, indicating that the dominant magnetic interactions are antiferromagnetic in origin. However, these interactions are of insufficient strength to produce long-range magnetic order and the material remains paramagnetic to the lowest temperature studied. Whilst the data for $\operatorname{Er}_{6} \mathrm{Cr}_{2} \mathrm{~S}_{11}$ also appear to be consistent with paramagnetic behaviour down to $5 \mathrm{~K}$ and lead to a very small positive Weiss constant, a significant deviation from Curie-Weiss behaviour is observed below $c a$. 20K. Subtraction of the contribution to the magnetic susceptibility arising from the erbium ions, assuming 
Curie-Weiss behaviour and an effective magnetic moment of $9.58 \mu_{\mathrm{B}}$, reveals an underlying antiferromagnetic transition, with $\mathrm{T}_{\mathrm{N}}=11.4 \mathrm{~K}$ (Figure $1(\mathrm{~b})$ ). This suggests ordering of the $\mathrm{Cr}^{2+}$ sub-lattice occurs on cooling, the signature of which is masked by the much larger magnetic response of the rare-earth ion. A similar subtraction applied to the data for $\mathrm{Er}_{4} \mathrm{CrS}_{7}$ does not reveal a corresponding ordering transition of the $\mathrm{Cr}^{2+}$ sub-lattice in this phase.

The magnetic susceptibility data for $\mathrm{Er}_{3} \mathrm{CrS}_{6}$, although exhibiting Curie-Weiss behaviour at high temperatures with a value of $\mu_{\mathrm{eff}}$ consistent with trivalent rare-earth and transition-metal cations, shows more complex behaviour at low temperatures, with slight divergence of $\mathrm{fc}$ and zfc data in the temperature range $5 \leq \mathrm{T} / \mathrm{K} \leq 45$. Moreover, on cooling below $50 \mathrm{~K}$, the $\chi(\mathrm{T})$ curve exhibits an inflection at $30 \mathrm{~K}$, followed by a steep rise at $10 \mathrm{~K}$, suggesting two successive magnetic transitions. Further support for this is provided by examination of the temperature dependence of the effective magnetic moment, $\mu_{\mathrm{eff}}$, per cation (Figure 2), as measured by the quantity $[(8 \chi \mathrm{T}) / 4]^{1 / 2}$. On cooling, $\mu_{\mathrm{eff}}$ remains close to the expected value for $\mathrm{Er}^{3+}$ and $\mathrm{Cr}^{3+}$ over a wide range of temperature, until at $c a .50 \mathrm{~K}$ it begins to increase markedly, reaching a maximum of $21.8 \mu_{\mathrm{B}}$ at $30 \mathrm{~K}$. Below this temperature $\mu_{\mathrm{eff}}$ falls, reaches a minimum at $9.4 \mathrm{~K}$, before increasing slightly on further cooling. Measurement of the magnetisation as a function of field confirms the existence of a spontaneous magnetization at 5K (Figure 3). This approaches saturation in an applied field of 10kG. The saturated moment was estimated by taking the intercept on the moment axis of linear fits to the high-field region of $\mu v s .1 / \mathrm{H}$ plots, leading to a value of 7.97(9) $\mu_{\mathrm{B}}$ per formula unit.

Two magnetic transitions are apparent at low temperature in the magnetic susceptibility data of $\mathrm{Er}_{2} \mathrm{CrS}_{4}$. The value of $\mu_{\mathrm{eff}}$, extracted from the Curie-Weiss fit to 
the high-temperature data, is consistent with the presence of $\mathrm{Er}^{3+}$ and $\mathrm{Cr}^{2+}$ ions. On cooling, the magnetic susceptibility shows a peak at $44 \mathrm{~K}$. Below $42 \mathrm{~K}, \chi$ rises and exhibits a second broad maximum at $9 \mathrm{~K}$, before rising again below $4 \mathrm{~K}$. The negative Weiss constant indicates that the dominant magnetic exchange interactions are antiferromagnetic in origin. The effective magnetic moment is almost invariant with temperature down to $c a$. 44K (Figure 4), below which $\mu_{\text {eff }}$ decreases markedly, suggesting that the peak in $\chi(\mathrm{T})$ at $42 \mathrm{~K}$ is associated with long-range antiferromagnetic ordering of the chromium sub-lattice; the second lower-temperature anomaly corresponding to ordering of the erbium sub-lattice. The magnetisation shows an almost linear dependence on magnetic field (Figure 3) and does not approach saturation even at the highest field used. This, together with the relatively low value of $c a .0 .5 \mu_{\mathrm{B}}$ per cation at $10 \mathrm{kG}$ indicates that there is no uncompensated moment associated with either the erbium or chromium sub-lattices.

\section{Discussion}

Single-crystal X-ray diffraction reveals that $\mathrm{Er}_{3} \mathrm{CrS}_{6}$ adopts the $\mathrm{U}_{3} \mathrm{ScS}_{6}$-type structure, ${ }^{30}$ with complete ordering of $\mathrm{Cr}^{3+}$ cations into the octahedral sites. It appears likely on the basis of powder X-ray diffraction data that other sulphides of stoichiometry $\mathrm{Ln}_{3} \mathrm{CrS}_{6}(\mathrm{Ln}=\mathrm{La}-\mathrm{Lu})^{4}$ are isostructural, although determination of the degree of $\mathrm{Ln}^{3+} / \mathrm{Cr}^{3+}$ ordering requires detailed structural measurements. While isostructural phases containing other transition metals have not been reported, it is possible to substitute chromium by indium, to form the closely related $\operatorname{Ln}_{3} \operatorname{In} S_{6}(\mathrm{Ln}=$ Sm to $\mathrm{Tb}$ ) phases. ${ }^{31,32}$ The structure of $\mathrm{Er}_{3} \mathrm{CrS}_{6}$ consists of $\left[\mathrm{CrS}_{4}\right]^{-}$chains of edgesharing $\mathrm{Cr}^{3+}$-centered octahedra directed along [001] (Figure 5). $\operatorname{Er}(1) \mathrm{S}_{8}$ polyhedra share opposite triangular faces to form $\mathrm{ErS}_{5}{ }^{5-}$ chains, also directed parallel to the 
crystallographic $c$-axis. The $\mathrm{ErS}_{5}{ }^{5-}$ chains share common edges and vertices with the $\mathrm{CrS}_{4}{ }^{5-}$ chains and serve to link the latter to form a slab parallel to the (100) plane. These slabs are connected in the [010] direction by $\operatorname{Er}(2) \mathrm{S}_{7}$ and $\operatorname{Er}(3) \mathrm{S}_{8}$ onedimensional chains, to generate a complex three-dimensional network. The erbiumsulphur matrix serves to isolate individual $\mathrm{CrS}_{4}{ }^{5-}$ chains from each other; the closest

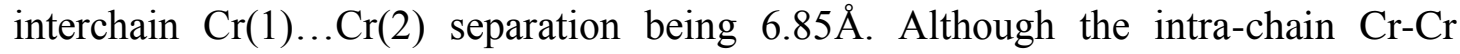
distances are considerably shorter at $3.733 \AA$, this is significantly greater than the critical distance $\left(\mathrm{R}_{\mathrm{C}} \approx 3.1 \AA\right)^{33}$ below which a direct $\mathrm{t}_{2 \mathrm{~g}}-\mathrm{t}_{2 \mathrm{~g}}$ interaction could occur. Intra-chain magnetic exchange is therefore through a $90^{\circ}$ superexchange interaction via an intervening sulphide anion. For the $t_{2 g}{ }^{3}$ configuration of $\mathrm{Cr}^{3+}$, the $90^{\circ} \mathrm{d}_{\pi}-\mathrm{p}_{\pi} / \mathrm{p}_{\sigma^{-}}$ $d_{\sigma}$ interaction is predicted to be ferromagnetic. ${ }^{33}$ This suggests that the magnetic transition that occurs at $30 \mathrm{~K}$ involves ferromagnetic ordering of the chromium ions within the $\mathrm{CrS}_{2}{ }^{-}$chains. On further cooling, the weaker interactions associated with the rare-earth ions become significant. This second anomaly at $11 \mathrm{~K}$ may therefore be associated with ordering of the erbium sub-lattice. The saturation moment of 7.97(9) $\mu_{\mathrm{B}}$ per formula unit at $5 \mathrm{~K}$ suggests that it arises from a single uncompensated erbium moment, for which the free-ion value, $g_{J} J=9 \mu_{\mathrm{B}}$. This would require the two crystallographically-distinct ferromagnetic chains of chromium-centred octahedra to be antiferromagnetically coupled and the moments associated with one of the erbium sub-lattices to be anti-parallel to that of the other two. Confirmation of this proposed model for the low-temperature magnetically ordered structure requires neutron diffraction measurements.

The structures of the remaining three erbium-chromium sulphides, $\mathrm{Er}_{2} \mathrm{CrS}_{4}, \mathrm{Er}_{6} \mathrm{Cr}_{2} \mathrm{~S}_{11}$ and $\mathrm{Er}_{4} \mathrm{CrS}_{7}$, investigated here are closely related. Structural relationships of ternary sulphides within the $\mathrm{MnS}-\mathrm{Er}_{2} \mathrm{~S}_{3}$ and $\mathrm{MnS}-\mathrm{Y}_{2} \mathrm{~S}_{3}$ pseudo-binary systems ${ }^{14,15}$ have 
previously been formulated on the basis of chemical twinning, ${ }^{34}$ in which a homologous series of phases may be generated from a parent rock-salt type structure through repeated reflection twinning on the $\{113\}$ planes. ${ }^{34,35}$ Whilst it has been proposed that this description could also be applied to describe ternary phases within the Cr-Er-S system, ${ }^{36}$ we suggest, on the basis of the crystallographic studies reported here, that the structures of these materials may be better considered as arising from common building blocks. This leads to identification of a structural evolution in these phases that suggest the three erbium-chromium sulphides characterised here may represent the first members of an extended family of materials.

The basic building unit in the structures of $\mathrm{Er}_{2} \mathrm{CrS}_{4}, \mathrm{Er}_{6} \mathrm{Cr}_{2} \mathrm{~S}_{11}$ and $\mathrm{Er}_{4} \mathrm{CrS}_{7}$ is the $\mathrm{MS}_{3}$ double octahedral chain (Figure 6(a)) analogous to the isolated $\mathrm{MSe}_{3}$ chains present in the structure of $\mathrm{CeCrSe}_{3} .{ }^{37}$ However, in the structures of the erbium-chromium sulphides determined here, these chains are linked through shared edges to form a two-dimensional slab of stoichiometry $\mathrm{M}_{2} \mathrm{~S}_{5}$ (Figure $6(\mathrm{~b})$ ), which serves as the building block for the structures of $\mathrm{Er}_{2} \mathrm{CrS}_{4}, \mathrm{Er}_{4} \mathrm{CrS}_{7}$ and $\mathrm{Er}_{6} \mathrm{Cr}_{2} \mathrm{~S}_{11}$.

In $\mathrm{Er}_{2} \mathrm{CrS}_{4}$, (Figure 6(c)) vertex linking of these slabs generates an $\mathrm{M}_{2} \mathrm{~S}_{4}$ framework of linked octahedra. The $\mathrm{Cr}^{2+}$ and $\mathrm{Er}^{3+}$ ions are ordered within the slabs such that they alternate along the [001] direction within the chains of metal-centred octahedra. The resulting anionic framework of stoichiometry $\left[\mathrm{CrErS}_{4}\right]^{3-}$ defines one-dimensional channels directed along [010], in which the seven-coordinate erbium cations, $\operatorname{Er}(1)$ and $\operatorname{Er}(2)$, that provide the charge-balancing reside. The complete ordering of $\mathrm{Cr}^{2+}$ and $\mathrm{Er}^{3+}$ in $\mathrm{Er}_{2} \mathrm{CrS}_{4}$ may be favoured by the Jahn-Teller distortion of $\mathrm{Cr}^{2+}: \mathrm{d}^{4}$.

The structure of $\mathrm{Er}_{2} \mathrm{CrS}_{4}$ is related to that of $\mathrm{CaTi}_{2} \mathrm{O}_{4}(\mathrm{Cmcm})^{38}$ and its Jahn-Teller distorted variant, $\mathrm{CaMn}_{2} \mathrm{O}_{4}(\mathrm{Pbcm}) .{ }^{39}$ On the basis of powder $\mathrm{X}$-ray diffraction, it was suggested that materials $\mathrm{Ln}_{2} \mathrm{MS}_{4}(\mathrm{Ln}=\mathrm{Tb}-\mathrm{Tm} ; \mathrm{M}=\mathrm{Mg}, \mathrm{Mn}, \mathrm{Fe})^{9}$ adopt a structure 
described in the space-group $\mathrm{Cmcm}$, which is closely related to that of $\mathrm{CaTi}_{2} \mathrm{O}_{4}$. A subsequent single-crystal $\mathrm{X}$-ray diffraction study on non-stoichiometric $\mathrm{Yb}_{2} \mathrm{MnS}_{4}$ confirms this close-relationship, although the structure was described in $C m c 2_{1 \cdot}{ }^{12}$ In contrast with the $\mathrm{Ln}_{2} \mathrm{MnS}_{4}$ structures, in which the rare-earth and the transition-metal atoms are disordered over all the available octahedral sites, in $\mathrm{Er}_{2} \mathrm{CrS}_{4}$ ordering of erbium and chromium atoms results in a doubling of the $b$-axis, together with a lowering of the symmetry to $\mathrm{P} 2{ }_{1} \mathrm{Ca}$. A similar enlargement of the unit cell has been identified, from powder X-ray diffraction data, for other $\mathrm{Ln}_{2} \mathrm{CrS}_{4}(\mathrm{Ln}=\mathrm{Y}, \mathrm{Ho}, \mathrm{Tm}$, $\mathrm{Yb}){ }^{40}$ suggesting that they are isostructural with $\mathrm{Er}_{2} \mathrm{CrS}_{4}$. This is supported by a recent powder neutron diffraction study on $\mathrm{Y}_{2} \mathrm{CrS}_{4}{ }^{41}$

The $\mathrm{M}_{2} \mathrm{~S}_{5}$ slab of metal-centred octahedra is also encountered in the structure of $\mathrm{Er}_{4} \mathrm{CrS}_{7}$ (Figure 6(d)), which is isostructural with the binary sulphides $\operatorname{Ln}_{5} \mathrm{~S}_{7 .}{ }^{5,29}$ The $\mathrm{M}_{2} \mathrm{~S}_{5}$ slabs in $\mathrm{Er}_{4} \mathrm{CrS}_{7}$ are not fused directly together as occurs in $\mathrm{Er}_{2} \mathrm{CrS}_{4}$, but are separated by one dimensional $\mathrm{MS}_{4}$ chains of edge-sharing octahedra, analogous to those present in $\mathrm{Er}_{3} \mathrm{CrS}_{6}$. However, despite the presence of $\mathrm{Cr}^{2+}: \mathrm{d}^{4}$, the $\mathrm{Er}^{3+}$ and $\mathrm{Cr}^{2+}$ cations are disordered over the octahedral sites. Refinements indicate that chromium cations show a preference for octahedral sites within the slab, which has a composition $\left(\operatorname{Er}_{0.60} \mathrm{Cr}_{0.40}\right)_{2} \mathrm{~S}_{5}^{4.8-}$, whereas ca. $75 \%$ of the octahedra in the singleoctahedral chains contain erbium cations. The resulting $\left[\mathrm{Er}_{2} \mathrm{CrS}_{7}\right]^{6-}$ framework, contains channels parallel to the crystallographic $b$-axis, in which are located additional $\mathrm{Er}^{3+}$ ions $(\operatorname{Er}(1))$ in a monocapped trigonal prismatic coordination geometry. The shortest cation-cation distances within the slab are $c a .3 .70 \AA$, slightly shorter than the intra-chain distances of $3.77 \AA$. The distribution of rare-earth and transition-metal cations is similar to that in the isostructural $\mathrm{Y}_{4} \mathrm{FeS}_{7}{ }^{5,6}$ and $\mathrm{Ho}_{4} \mathrm{FeS}_{7}{ }^{6}$ 
the only two examples of this structure type for which detailed structural characterisation has been performed to date.

In the structure of $\mathrm{Er}_{6} \mathrm{Cr}_{2} \mathrm{~S}_{11}$ (Figure 6(e)), pairs of $\mathrm{M}_{2} \mathrm{~S}_{5}$ units are fused to create a double slab. There is disorder of $\mathrm{Er}^{3+}$ and $\mathrm{Cr}^{2+}$ cations over the available sites within this network of octahedra, with $c a .85 \%$ of the chromium cations residing in sites within the slab, whilst the ratio of $\mathrm{Er}^{3+}: \mathrm{Cr}^{2+}$ within the octahedral chains is similar to that in $\mathrm{Er}_{4} \mathrm{CrS}_{7}$ at 3:1. Successive double slabs are linked by sharing common vertices with single $\mathrm{MS}_{4}$ octahedral chains to produce a framework of composition $\left[\mathrm{Er}_{3} \mathrm{Cr}_{2} \mathrm{~S}_{11}\right]^{9-}$. This network of octahedra contains two types of channel running parallel to the crystallographic $a$-axis. The channels are occupied by six-coordinate $\operatorname{Er}(1)$ and seven-coordinate $\operatorname{Er}(2)$ cations which serve to balance the charge of the framework. This structure is analogous to that of the binary sulphide $\mathrm{Tm}_{8} \mathrm{~S}_{11}$, ${ }^{42}$ whilst the degree of disorder of $\mathrm{Er}^{3+}$ and $\mathrm{Cr}^{2+}$ over the octahedral sites is similar to that of $\mathrm{Yb}^{3+}$ and $\mathrm{Fe}^{2+}$ in $\mathrm{Yb}_{6} \mathrm{Fe}_{2} \mathrm{~S}_{11} \cdot{ }^{16}$ To our knowledge, the $\mathrm{Ln}_{8} \mathrm{~S}_{11}$ stoichiometry has not been observed for any other binary rare-earth sulphide. However, the lattice parameters of the ternary compounds $\operatorname{Ln}_{6} \mathrm{Mn}_{2} \mathrm{~S}_{11}(\mathrm{Ln}=\mathrm{Y}, \mathrm{Er})^{14,15}$ and $\mathrm{Yb}_{6} \mathrm{Mg}_{2} \mathrm{~S}_{11}{ }^{43}$ determined by electron diffraction, suggest they crystallise in the same structural type. Whilst the synthesis of the ternary chromium sulphides $\operatorname{Ln}_{6} \mathrm{Cr}_{2} \mathrm{~S}_{11}(\mathrm{Ln}=\mathrm{Gd}, \mathrm{Tb}, \mathrm{Ho})$, has been described, ${ }^{15}$ structural characterisation is yet to be performed.

The presence of $\mathrm{M}_{2} \mathrm{~S}_{5}$ slabs of variable thickness in the structures of each of the ternary phases, $\mathrm{Er}_{2} \mathrm{CrS}_{4}, \mathrm{Er}_{6} \mathrm{Cr}_{2} \mathrm{~S}_{11}$ and $\mathrm{Er}_{4} \mathrm{CrS}_{7}$ suggests a common description can be applied to the structure of these materials. The slabs provide a structural component, $\left[\mathrm{M}_{2 \mathrm{n}} \mathrm{S}_{4 \mathrm{n}+1}\right]$. This unit shares terminal sulphide ions with $\mathrm{MS}_{4}$ chains of edge-linked octahedra, to generate an anionic framework that may be expressed by the general formula, $\left[\mathrm{M}_{2 \mathrm{n}+1} \mathrm{~S}_{4 \mathrm{n}+3}\right]^{x-}$, where the charge, $x$, is determined by the oxidation state of 
chromium and the $\mathrm{Ln} / \mathrm{Cr}$ ratio within the framework. The charge balance is provided by additional rare-earth cations which reside at sites of higher coordination number within one-dimensional channels defined by the framework. The anionic network of $\mathrm{Er}_{4} \mathrm{CrS}_{7}$ and $\mathrm{Er}_{6} \mathrm{Cr}_{2} \mathrm{~S}_{11}$ can thus be considered the $\mathrm{n}=1$ and $\mathrm{n}=2$ members of a homologous series, whilst $\mathrm{Er}_{2} \mathrm{CrS}_{4}$ in which the single octahedral chains are absent is the $n=\infty$ end-member of this family.

The magnetic properties of the $n=1,2$, and $\infty$ members of this family of ternary phases show significant variation, which can be related to the detailed structure and, in particular, degree of cation ordering. The paramagnetism of $\mathrm{Er}_{4} \mathrm{CrS}_{7}$ may be traced to the disorder of $\mathrm{Er}^{3+}$ and $\mathrm{Cr}^{2+}$ over sites in the $\mathrm{Er}_{3} \mathrm{CrS}_{7}^{3-}$ framework. In particular the occupancy of only $40 \%$ of the sites in the slab by $\mathrm{Cr}^{2+}$ ions may be sufficient to prevent a long-range magnetic exchange pathway from being established. By contrast, in $\mathrm{Er}_{6} \mathrm{Cr}_{2} \mathrm{~S}_{11}$ where the fraction of octahedral sites occupied by $\mathrm{Cr}^{2+}$ in the double slab is only marginally higher at $42 \%$, the degree of coverage appears to exceed the percolation threshold for this topology and magnetic ordering of $\mathrm{Cr}^{2+}$ cations appears to occur at low temperatures. Given the cation disorder, we cannot exclude the possibility of a fraction of the erbium ions also being involved in this transition. Further evidence for long-range order below $11.4 \mathrm{~K}$ in $\mathrm{Er}_{6} \mathrm{Cr}_{2} \mathrm{~S}_{11}$ is provided by preliminary powder neutron diffraction data ${ }^{44}$ collected at 4, 8 and 14K (Figure 7), which reveal that weak reflections present in the $4 \mathrm{~K}$ data at 3.14 and $3.17 \AA$, together with diffuse scattering centered at $c a .5 \AA$, disappear on heating through the temperature of the maximum in $\chi(\mathrm{T})$.

The complete $\mathrm{Cr}^{2+} / \mathrm{Er}^{3+}$ cation ordering that occurs in $\mathrm{Er}_{2} \mathrm{CrS}_{4}$ results in a zig-zag magnetic exchange pathway between $\operatorname{Cr}(5)$ and $\operatorname{Cr}(6)$ ions within the double chains of octahedra that constitute the $\operatorname{ErCrS}_{5}{ }^{5-}$ slab (Figure 8). These interactions are via 
intervening sulphide anions and are of the $180^{\circ}$ superexchange type, involving long and short Cr-S bonds on either side of the anion. The magnitude of the Jahn-Teller distortion $\left(\mathrm{d}_{\mathrm{ax}} / \mathrm{d}_{\mathrm{eq}} \approx 1.14\right)$, suggests that the $\mathrm{e}_{\mathrm{g}}$ electron density of $\mathrm{Cr}^{2+}$ is located in $\mathrm{dz}^{2}$ orbitals. Therefore exchange between $\operatorname{Cr}(5)$ and $\operatorname{Cr}(6)$ occurs through overlap of a filled $\mathrm{dz}^{2}$ and empty $\mathrm{dx}^{2}-\mathrm{y}^{2}$ with the p-orbital of a sulphide anion. The $\sigma$-interaction is predicted to be ferromagnetic in origin, with a moderate antiferromagnetic $\pi$ component. ${ }^{33}$ There are additional intra-slab $90^{\circ}$ antiferromagnetic $d_{\sigma}-p_{\sigma} / p_{\pi}-d_{\pi}$ superexchange interactions between chromium ions located in adjacent double chains. These predictions would suggest that within the $\mathrm{ErCrS}_{5}{ }^{5-}$ slab, chromium ions within a given octahedral chain should be ferromagnetically ordered along the [010] direction, with antiferromagnetic coupling between adjacent chains within the double chain. The double chains would in turn be antiferromagnetically coupled. Inter-slab interactions between chromium cations occur via the erbium-centred octahedra and are therefore likely to be weaker in strength.

In conclusion, we have demonstrated that the magnetic properties of erbiumchromium sulphides are influenced by the degree of rare-earth/transition-metal ordering. In particular on cooling, successive transitions associated with the chromium and erbium sub-lattices are observed in $\mathrm{Er}_{3} \mathrm{CrS}_{6}$ and $\mathrm{Er}_{2} \mathrm{CrS}_{4}$ in which cation ordering is complete, suggesting an interaction between the $d$ - and $f$-electrons of the two types of cation. The cation-disordered phase $\mathrm{Er}_{6} \mathrm{Cr}_{2} \mathrm{~S}_{11}$, shows magnetic ordering of the chromium sub-lattice only. Characterisation of the magneticallyordered ground states of these materials will require detailed neutron diffraction measurements to be performed as a function of temperature. Significantly, we have shown by single-crystal X-ray diffraction that the structures of $\mathrm{Er}_{2} \mathrm{CrS}_{4}, \mathrm{Er}_{6} \mathrm{Cr}_{2} \mathrm{~S}_{11}$ and $\mathrm{Er}_{4} \mathrm{CrS}_{7}$ may be described in terms of a common building block. This suggests that 
synthesis of new members of this family of materials, containing thicker slabs of octahedra, may be possible. We are currently pursuing this line of investigation.

\section{Acknowledgements}

Financial support from The Royal Society through provision of a Joint Project Grant is gratefully acknowledged. PV thanks the UK Engineering and Physical Sciences Research Council for the award of an Advanced Research Fellowship and IS thanks Heriot-Watt University for a studentship.

Supporting Information Available: Tables of significant bond distances and cif files for each of the single-crystal structure determinations. This information is available free of charge via the Internet at http://pubs.acs.org. 


\section{References}

${ }^{1}$ Rouxel, J., in Physics and Chemistry of Low-Dimensional Inorganic Conductors

(Eds C. Schlenker, J. Dumas, M. Greenblatt and S. van Smaalen), NATO ASI Series B, 1996, 354, 1 .

${ }^{2}$ Pearce, C.I., Pattrick, R.A.D., Vaughan, D.J., Rev. Mineral. Geochem., 2006, 61, 127.

${ }^{3}$ Mitchell, K.; Ibers, J. A. Chem. Rev., 2002, 102, 1929.

${ }^{4}$ Rustamov, P.G.; Kurbanov, T. Kh.; Aliev, O. M.; Aliev, I. P. Inorg. Mater., 1984 $20,1664$.

5 Adolphe, C. Ann. Chim., 1965, 10, 271.

${ }^{6}$ Adolphe, C.; Laruelle, P. Bull. Soc. Fr. Mineral. Cristallogr., 1968, 91, 219.

${ }^{7}$ Collin, G.; Rouyer, F.; Loriers, J. C.R. Acad. Sci. Paris, Series C, 1968, 266, 689.

${ }^{8}$ Mills, A. M.; Ruck, M. Acta Cryst. C, 2004, 60, i71.

${ }^{9}$ Patrie, M.; Chevalier, R. C.R. Acad. Sci. Paris, Series C, 1966, 263, 1061.

${ }^{10}$ Litteer, J. B.; Sirchio, S. A.; Fettinger, J. C.; Smolyaninova, V. ; Eichhorn, B. W.;

Greene, R. L. Chem. Mater., 1999, 11, 1179.

${ }^{11}$ Mills, A. M.; Bräunling, D.; Ruck, M. Acta Cryst. C, 2006, 62, i70.

${ }^{12}$ Lemoine, P.P.; Tomas, A.; Guittard, M. Acta Cryst. C, 1992, 48, 774.

${ }^{13}$ Tomas, A.; Chevalier, R.; Laurelle, P.; Bachet, B. Acta Cryst. B, 1976, 32, 3287.

${ }^{14}$ Landa-Canovas, A. R.; Otero-Diaz, L. C. Aust. J. Chem., 1992, 45, 1473.

${ }^{15}$ Bakker, M.; Hyde, B. G. Philos. Mag. A, 1978, 38, 615

${ }^{16}$ Chaqour, S. M.; Tomas, A.; Lemoine, P.; Palazzi, M.; Guittard, M. Acta Cryst. $C$, 1994, 50, 1655 .

${ }^{17}$ Tomas, A.; Rigoult, J.; Guittard, M.; Laruelle, P. Acta Cryst. B, 1980, 36, 1987.

${ }^{18}$ Bruker X8 APEX 2, Version 1.0-8, Bruker AXS Inc. Madison, WI USA, 2003. 
${ }^{19}$ Altomare, A.; Cascarano, G; Giacovazzo, C.; Guagliardi, A.; Burla, M.C.; Polidori, G.; Camelli, M. J. Appl. Crystallogr., Sect. A., 1994, 27, 435.

${ }^{20}$ Watkin, D.J.; Prout, C.K.; Carruthers, J.R.; Betteridge, P.W. in CRYSTALS Issue 10, Chemical Crystallography Laboratory, University of Oxford, UK 1996.

${ }^{21}$ Carruthers, J.R.; Watkin, D.J. Acta Cryst. A, 1979, 35, 698.

${ }^{22}$ Fang, C. M.; Meetsma, A.; Wiegers, G. A.; Boom, G. J. Alloys Comp., 1993, 201, 255.

${ }^{23}$ Brese, N.E.; O’Keeffe, M. Acta Cryst. B, 1991, 47, 192.

${ }^{24}$ Day, P; Hutchings, M.T; Janke, E; Walker, P.J. J.C.S. Chem. Commun, 1979, 711.

${ }^{25}$ Crama, W.J.; Maaskant, W.J.A; Verschoor, G.C, Acta Cryst. B, 1978, 34, 1973.

${ }^{26}$ Jellinek, F. Acta Cryst., 1957, 10, 620.

${ }^{27}$ Speck, A.L. J. Appl. Cryst., 2003, 36, 7.

${ }^{28}$ Speck, A.L. J. Appl. Cryst., 1988, 21, 578.

${ }^{29}$ Range, K.J.; Rau, F.; Klement, U. Z. Kristallogr., 1993, 208, 97.

${ }^{30}$ Rodier, N.; Tien, V. Acta Cryst. B, 1976, 32, 2705.

${ }^{31}$ Messain, D.; Carré, D.; Laurelle, P. Acta Cryst. B, 1977, 33, 2540.

${ }^{32}$ Guittard, M.; Carré, D.; Kabré, T. S. Mater. Res. Bull., 1978, 13, 279.

${ }^{33}$ Goodenough, J.B. in Magnetism and the Chemical Bond, Wiley, New York, (1963).

${ }^{34}$ Hyde, B. G.; Andersson, S.; Bakker, M.; Plug, C. M.; O’Keeffe, M. Prog. Solid State Chem., 1979, 12, 273.

${ }^{35}$ Ferraris, G.; Makovicky, E.; Merlino, S. Crystallography of Modular Materials, Oxford University Press, 2004.

${ }^{36}$ Tomas, A.; Guittard, M. Mat. Res. Bull., 1980, 15, 1547.

${ }^{37}$ Nguyen, H.D.; Etienne, J.; Laruelle, P. Bull. Soc. Chim. Fr., 1971, 2433.

${ }^{38}$ Bertaut, E.F.; Blum, P. Acta Cryst., 1956, 9, 121. 
${ }^{39}$ Giesber, H. G.; Pennington, W. T.; Kolis, J. W. Acta Cryst. C, 2001, 57, 329.

${ }^{40}$ Tomas, A.; Guittard, M.; Chevalier, R.; Flahaut, J. C.R. Acad. Sci. Paris, Series C, 1976, 282, 587.

${ }^{41}$ Tezuka, K.; Shan, Y. J.; Imoto, H.; Ohoyama, K. J. Phys. Chem. Solids, 2007, 68, 2133.

${ }^{42}$ Zhang, Y.; Franzen, H. F.; Harbrecht, B. J. Less-Common Metals, 1990, 166, 135.

${ }^{43}$ Urones-Garrote, E.; Gómez-Herrero, A.; Landa-Cánovas, A. R.; Otero-Díaz, L. C. Eur. J. Inorg. Chem., 2006, 1436.

${ }^{44}$ Powder neutron diffraction data were collected on the Polaris diffractometer at the ISIS spallation source. The data shown were collected at a scattering angle of $90^{\circ}$ iv $2 \theta$. 
Table 1: Crystallographic Data for Ternary Erbium Chromium Sulphides Investigated by Single-Crystal X-ray Diffraction

\begin{tabular}{|c|c|c|c|c|}
\hline Formula & $\mathrm{Er}_{3} \mathrm{CrS}_{6}$ & $\mathrm{Er}_{2} \mathrm{CrS}_{4}$ & $\mathrm{Er}_{6} \mathrm{Cr}_{2} \mathrm{~S}_{11}$ & $\mathrm{Er}_{4} \mathrm{CrS}_{7}$ \\
\hline $\mathrm{M}_{\mathrm{r}}$ & 746.17 & 514.78 & 1462.48 & 940.93 \\
\hline Crystal Habit & Black needle & Black needle & Black needle & Black block \\
\hline Dimensions/mm & $0.5 \times 0.04 \times 0.04$ & $0.2 \times 0.04 \times 0.02$ & $0.26 \times 0.08 \times 0.06$ & $0.16 \times 0.08 \times 0.05$ \\
\hline Crystal System & Orthorhombic & Orthorhombic & Orthorhombic & Monoclinic \\
\hline Space group & Pnnm & $P 2_{1} c a$ & $\mathrm{Cmcm}$ & $C 2 / m$ \\
\hline $\mathrm{T} / \mathrm{K}$ & 293 & 293 & 293 & 293 \\
\hline$a / \AA$ & 13.192(2) & $12.4629(11)$ & $3.7551(3)$ & $12.5057(5)$ \\
\hline$b / \AA$ & 15.819(3) & $7.4882(6)$ & $12.5190(8)$ & $3.7650(2)$ \\
\hline$c / \AA$ & $3.7333(6)$ & $12.4937(11)$ & $34.177(2)$ & $11.2740(4)$ \\
\hline$\beta /^{\circ}$ & 90.0 & 90.0 & 90.0 & $105.85(2)$ \\
\hline $\mathrm{V} / \AA^{3}$ & $779.1(2)$ & $1165.97(17)$ & $1606.7(2)$ & $510.64(4)$ \\
\hline$Z$ & 4 & 8 & 4 & 2 \\
\hline Wavelength/ $\AA$ & 0.71073 & 0.71073 & 0.71073 & 0.71073 \\
\hline$\mu / \mathrm{mm}^{-1}$ & 34.848 & 31.636 & 33.749 & 34.618 \\
\hline Measured data & 17332 & 3248 & 18621 & 6925 \\
\hline Unique data & 2087 & 3248 & 1410 & 878 \\
\hline $\begin{array}{l}\text { Observed data } \\
(I>3 \sigma(I))\end{array}$ & 1729 & 1528 & 1086 & 735 \\
\hline $\mathrm{R}_{\text {merg }}$ & 0.0371 & 0.0320 & 0.0484 & 0.0313 \\
\hline $\mathrm{R}\left(\mathrm{F}_{\mathrm{o}}\right)^{\mathrm{a}}$ & 0.0186 & 0.0328 & 0.0229 & 0.0332 \\
\hline $\mathrm{R}_{\mathrm{w}}\left(\mathrm{F}_{\mathrm{o}}\right)^{\mathrm{b}}$ & 0.0188 & 0.0128 & 0.0235 & 0.0279 \\
\hline
\end{tabular}

${ }^{\mathrm{a}} \mathrm{R}\left(\mathrm{F}_{\mathrm{o}}\right)=\Sigma\left(\left|\mathrm{F}_{\mathrm{o}}\right|-\left|\mathrm{F}_{\mathrm{c}}\right|\right) / \Sigma\left|\mathrm{F}_{\mathrm{o}}\right| ;{ }^{\mathrm{b}} \mathrm{R}_{\mathrm{w}}\left(\mathrm{F}_{\mathrm{o}}\right)=\left[\Sigma \mathrm{w}\left(\left|\mathrm{F}_{\mathrm{o}}\right|-\left|\mathrm{F}_{\mathrm{c}}\right|\right)^{2} / \Sigma \mathrm{w}\left|\mathrm{F}_{\mathrm{o}}\right|^{2}\right]^{1 / 2}$. 
Table 2: Final Refined Coordinates and Equivalent Isotropic Displacement Parameters for $\mathrm{Er}_{3} \mathrm{CrS}_{6}$

\begin{tabular}{|l|c|c|c|c|c|}
\hline Atom & Site & $\mathrm{x}$ & $\mathrm{y}$ & $\mathrm{z}$ & $\mathrm{U}_{\mathrm{eq}}\left(\AA^{2}\right)$ \\
\hline $\operatorname{Er}(1)$ & $4(g)$ & $0.54922(1)$ & $0.22090(1)$ & 0 & $0.0042(1)$ \\
\hline $\operatorname{Er}(2)$ & $4(g)$ & $0.31855(1)$ & $0.35227(1)$ & 0 & $0.0041(1)$ \\
\hline $\operatorname{Er}(3)$ & $4(g)$ & $0.25639(1)$ & $0.09874(1)$ & $-1 / 2$ & $0.0048(1)$ \\
\hline $\operatorname{Cr}(4)$ & $2(a)$ & $1 / 2$ & $1 / 2$ & $-1 / 2$ & $0.0033(2)$ \\
\hline $\operatorname{Cr}(5)$ & $2(c)$ & $1 / 2$ & 0 & $-1 / 2$ & $0.0028(2)$ \\
\hline $\mathrm{S}(6)$ & $4(g)$ & $0.41659(8)$ & $0.07611(7)$ & 0 & $0.0051(2)$ \\
\hline $\mathrm{S}(7)$ & $4(g)$ & $0.62050(8)$ & $0.10867(7)$ & $-1 / 2$ & $0.0052(2)$ \\
\hline $\mathrm{S}(8)$ & $4(g)$ & $0.68796(8)$ & $0.28959(7)$ & $1 / 2$ & $0.0050(2)$ \\
\hline $\mathrm{S}(9)$ & $4(g)$ & $0.39569(8)$ & $0.24634(7)$ & $-1 / 2$ & $0.0048(2)$ \\
\hline $\mathrm{S}(10)$ & $4(g)$ & $0.52197(8)$ & $0.40137(7)$ & 0 & $0.0051(2)$ \\
\hline $\mathrm{S}(11)$ & $4(g)$ & $0.31847(8)$ & $0.47972(7)$ & $1 / 2$ & $0.0051(2)$ \\
\hline
\end{tabular}


Table 3: Final Refined Coordinates and Equivalent Isotropic Displacement Parameters for $\mathrm{Er}_{2} \mathrm{CrS}_{4}$

\begin{tabular}{|l|l|c|c|c|c|}
\hline Atom & Site & $\mathrm{x}$ & $\mathrm{y}$ & $\mathrm{z}$ & $\mathrm{U}_{\mathrm{eq}}\left(\AA^{2}\right)$ \\
\hline $\operatorname{Er}(1)$ & $4(a)$ & $0.58027(12)$ & $0.6365(3)$ & $1.13561(14)$ & $0.0098(4)$ \\
\hline $\operatorname{Er}(2)$ & $4(a)$ & $0.57184(11)$ & $1.1359(3)$ & $1.13675(15)$ & $0.0116(4)$ \\
\hline $\operatorname{Er}(3)$ & $4(a)$ & $0.7458(2)$ & $0.8843(3)$ & $1.37394(9)$ & $0.0094(3)$ \\
\hline $\operatorname{Er}(4)$ & $4(a)$ & $0.8845(2)$ & $0.6139(3)$ & $1.61095(9)$ & $0.0094(3)$ \\
\hline $\operatorname{Cr}(5)$ & $4(a)$ & $0.8792(8)$ & $1.1153(11)$ & $1.6094(3)$ & $0.0105(9)$ \\
\hline $\operatorname{Cr}(6)$ & $4(a)$ & $0.7495(7)$ & $1.3822(12)$ & $1.3771(3)$ & $0.0098(8)$ \\
\hline $\mathrm{S}(7)$ & $4(a)$ & $0.5498(4)$ & $0.8824(17)$ & $1.2896(5)$ & $0.0086(11)$ \\
\hline $\mathrm{S}(8)$ & $4(a)$ & $0.9380(5)$ & $0.8836(14)$ & $1.4728(4)$ & $0.0096(10)$ \\
\hline $\mathrm{S}(9)$ & $4(a)$ & $0.4322(5)$ & $0.3878(13)$ & $1.0477(4)$ & $0.0087(10)$ \\
\hline $\mathrm{S}(10)$ & $4(a)$ & $0.6933(5)$ & $0.6167(15)$ & $1.5128(5)$ & $0.0086(10)$ \\
\hline $\mathrm{S}(11)$ & $4(a)$ & $0.7984(6)$ & $1.1502(8)$ & $1.2453(5)$ & $0.0120(10)$ \\
\hline $\mathrm{S}(12)$ & $4(a)$ & $0.7990(5)$ & $0.6476(8)$ & $1.2263(5)$ & $0.0100(10)$ \\
\hline $\mathrm{S}(13)$ & $4(a)$ & $0.7004(5)$ & $1.1151(13)$ & $1.5305(4)$ & $0.0088(10)$ \\
\hline $\mathrm{S}(14)$ & $4(a)$ & $0.5735(5)$ & $0.3902(16)$ & $1.2921(5)$ & $0.0094(10)$ \\
\hline
\end{tabular}


Table 4: Final Refined Coordinates and Equivalent Isotropic Displacement Parameters for $\mathrm{Er}_{6} \mathrm{Cr}_{2} \mathrm{~S}_{11}$

\begin{tabular}{|l|c|c|c|c|c|c|}
\hline Atom & Site & $\mathrm{x}$ & $\mathrm{y}$ & $\mathrm{z}$ & $\mathrm{U}_{\mathrm{eq}}\left(\AA^{2}\right)$ & $\mathrm{SOF}$ \\
\hline $\operatorname{Er}(1)$ & $4(c)$ & 0 & $0.49117(3)$ & $1 / 4$ & $0.0159(1)$ & \\
\hline $\operatorname{Er}(2)$ & $8(f)$ & $1 / 2$ & $0.75959(2)$ & $0.43838(1)$ & $0.0093(1)$ & \\
\hline $\mathrm{M}(3)$ & $8(f)$ & 0 & $0.74867(3)$ & $0.31710(1)$ & $0.0093(1)$ & $\begin{array}{l}\mathrm{Er}: 0.583(3) \\
\mathrm{Cr}: 0.417(3)\end{array}$ \\
\hline $\mathrm{M}(4)$ & $8(f)$ & $1 / 2$ & $0.51374(3)$ & $0.36581(1)$ & $0.0086(1)$ & $\begin{array}{l}\text { Er:0.569(3) } \\
\text { Cr:0.431(3) }\end{array}$ \\
\hline $\mathrm{M}(5)$ & $4(a)$ & $1 / 2$ & $1 / 2$ & $1 / 2$ & $0.0071(1)$ & $\begin{array}{l}\text { Er:0.714(4) } \\
\mathrm{Cr}: 0.286(4)\end{array}$ \\
\hline $\mathrm{S}(6)$ & $8(f)$ & $1 / 2$ & $0.60363(14)$ & $0.29733(5)$ & $0.0146(4)$ & \\
\hline $\mathrm{S}(7)$ & $4(c)$ & $1 / 2$ & $0.33818(17)$ & $1 / 4$ & $0.0154(6)$ & \\
\hline $\mathrm{S}(8)$ & $8(f)$ & 0 & $0.65877(13)$ & $0.38691(5)$ & $0.0122(4)$ & \\
\hline $\mathrm{S}(9)$ & $8(f)$ & $1 / 2$ & $0.41348(12)$ & $0.43103(5)$ & $0.0119(4)$ & \\
\hline $\mathrm{S}(10)$ & $8(f)$ & 0 & $0.64706(10)$ & $0.48397(4)$ & $0.0068(3)$ & \\
\hline $\mathrm{S}(11)$ & $8(f)$ & $1 / 2$ & $0.88752(17)$ & $0.33672(8)$ & $0.0303(6)$ & \\
\hline
\end{tabular}


Table 5: Final Refined Coordinates and Equivalent Isotropic Displacement Parameters for $\mathrm{Er}_{4} \mathrm{CrS}_{7}$

\begin{tabular}{|l|c|c|c|c|c|c|}
\hline Atom & Site & $\mathrm{x}$ & $\mathrm{y}$ & $\mathrm{z}$ & $\mathrm{U}_{\text {eq }}\left(\AA^{2}\right)$ & $\mathrm{SOF}$ \\
\hline $\mathrm{Er}(1)$ & $4(i)$ & $0.30774(3)$ & 0 & $0.19747(3)$ & $0.0129(1)$ & \\
\hline $\mathrm{M}(2)$ & $2(a)$ & $1 / 2$ & $1 / 2$ & 0 & $0.0103(2)$ & $\begin{array}{c}\text { Er: } 0.763(6) \\
\text { Cr: } 0.237(6)\end{array}$ \\
\hline $\mathrm{M}(3)$ & $4(i)$ & $0.61409(4)$ & $1 / 2$ & $0.42473(4)$ & $0.0106(1)$ & $\begin{array}{c}\text { Er: } 0.599(4) \\
\text { Cr: } 0.401(4)\end{array}$ \\
\hline $\mathrm{S}(4)$ & $4(i)$ & $0.16018(15)$ & $1 / 2$ & $0.05072(17)$ & $0.0100(4)$ & \\
\hline $\mathrm{S}(5)$ & $4(i)$ & $0.46519(16)$ & $1 / 2$ & $0.21708(19)$ & $0.0149(5)$ & \\
\hline $\mathrm{S}(6)$ & $4(i)$ & $0.75938(17)$ & $1 / 2$ & $0.64334(18)$ & $0.0150(5)$ & \\
\hline $\mathrm{S}(7)$ & $4(i)$ & $0.4861(4)$ & 0 & $0.4814(4)$ & $0.0184(8)$ & $0.5(-)$ \\
\hline
\end{tabular}


Table 6: Lattice Parameters of Bulk Samples of Erbium-Chromium Sulphides Determined by Powder X-ray Diffraction

\begin{tabular}{|l|l|l|l|l|}
\hline & \multicolumn{1}{|c|}{$a / \AA$} & \multicolumn{1}{c|}{$b / \AA$} & \multicolumn{1}{c|}{$c / \AA$} & \multicolumn{1}{c|}{$\beta /^{\circ}$} \\
\hline $\mathrm{Er}_{3} \mathrm{CrS}_{6}$ & $13.1815(4)$ & $15.8363(5)$ & $3.7293(2)$ & $90.0(-)$ \\
\hline $\mathrm{Er}_{2} \mathrm{CrS}_{4}$ & $12.4463(5)$ & $7.4892(3)$ & $12.4839(6)$ & $90.0(-)$ \\
\hline $\mathrm{Er}_{6} \mathrm{Cr}_{2} \mathrm{~S}_{11}$ & $3.7568(3)$ & $12.513(1)$ & $34.121(3)$ & $90.0(-)$ \\
\hline $\mathrm{Er}_{4} \mathrm{CrS}_{7}$ & $12.5007(9)$ & $3.7602(3)$ & $11.2637(8)$ & $105.977(5)$ \\
\hline
\end{tabular}


Table 7: Magnetic Properties of Erbium-Chromium Sulphides Derived From Fits to a Curie-Weiss Expression

\begin{tabular}{|l|l|l|l|l|l|l|}
\hline Material & $\begin{array}{l}\text { Fitting } \\
\text { Range/ } \mathrm{K}\end{array}$ & $\begin{array}{l}\mathrm{C}_{\mathrm{exp}} / \\
\mathrm{cm}^{3} \mathrm{~K} \mathrm{~mol}^{-1}\end{array}$ & $\begin{array}{l}\mathrm{C}_{\mathrm{th}} / \\
\mathrm{cm}^{3} \mathrm{~K} \mathrm{~mol}^{-1}\end{array}$ & $\mu_{\mathrm{eff}} / \mu_{\mathrm{B}}$ & $\mu_{\mathrm{th}} / \mu_{\mathrm{B}}$ & $\theta / \mathrm{K}$ \\
\hline $\mathrm{Er}_{3} \mathrm{CrS}_{6}$ & $80-300$ & $34.32(4)$ & 36.3 & $8.28(1)$ & 8.52 & $+8.0(2)$ \\
\hline $\mathrm{Er}_{2} \mathrm{CrS}_{4}$ & $80-300$ & $27.47(15)$ & 25.95 & $8.56(3)$ & 8.31 & $-10(1)$ \\
\hline $\mathrm{Er}_{4} \mathrm{CrS}_{7}$ & $88-300$ & $49.46(13)$ & 48.9 & $8.90(1)$ & 8.85 & $-6.4(5)$ \\
\hline $\mathrm{Er}_{6} \mathrm{Cr}_{2} \mathrm{~S}_{11}$ & $88-300$ & $72.15(16)$ & 74.9 & $8.49(1)$ & 8.65 & $+2.4(4)$ \\
\hline
\end{tabular}




\section{Figure Captions}

\begin{tabular}{|c|c|}
\hline Figure 1 & $\begin{array}{l}\text { Magnetic susceptibility data for (a) } \mathrm{Er}_{4} \mathrm{CrS}_{7} \text {; (b) } \mathrm{Er}_{6} \mathrm{Cr}_{2} \mathrm{~S}_{11} \text {; (c) } \mathrm{Er}_{3} \mathrm{CrS}_{6} \text { and } \\
\text { (d) } \mathrm{Er}_{2} \mathrm{CrS}_{4} \text {. Solid points denote field-cooled data and open points zero- } \\
\text { field cooled data. In (a) and (b), open triangles represent the magnetic } \\
\text { susceptibilities obtained following subtraction of the contribution due to } \\
\text { the erbium moments. The insets show the fit of a Curie-Weiss expression } \\
\text { to high-temperature data collected using a vibrating sample magnetometer. }\end{array}$ \\
\hline Figure 2 & $\begin{array}{l}\text { Temperature dependence of the effective magnetic moment per cation of } \\
\mathrm{Er}_{3} \mathrm{CrS}_{6} \text {, as measured by the quantity }(8 \chi \mathrm{T} / 4)^{1 / 2} \text {. }\end{array}$ \\
\hline Figure 3 & $\begin{array}{l}\text { Variation in the magnetic moment per formula unit of } \mathrm{Er}_{3} \mathrm{CrS}_{6} \text { (solid } \\
\text { points) and } \mathrm{Er}_{2} \mathrm{CrS}_{4} \text { (open points) as a function of applied magnetic field at } \\
5 \mathrm{~K} \text {. }\end{array}$ \\
\hline Figure 4 & $\begin{array}{l}\text { Temperature dependence of the effective magnetic moment per cation of } \\
\mathrm{Er}_{2} \mathrm{CrS}_{4} \text {, as measured by the quantity }(8 \chi \mathrm{T} / 3)^{1 / 2} \text {. }\end{array}$ \\
\hline Figure 5 & $\begin{array}{l}\text { Polyhedral representation of the crystal structure of } \mathrm{Er}_{3} \mathrm{CrS}_{6} \text { viewed along } \\
\text { [001]. } \mathrm{CrS}_{6} \text { octahedra are coloured cyan, erbium cations are represented by } \\
\text { magenta circles and sulphide anions by yellow circles. }\end{array}$ \\
\hline Figure 6 & $\begin{array}{l}\text { The relationship between the structures of } \mathrm{Er}_{4} \mathrm{CrS}_{7}, \mathrm{Er}_{6} \mathrm{Cr}_{2} \mathrm{~S}_{11} \text { and } \mathrm{Er}_{2} \mathrm{CrS}_{4} \text { : } \\
\text { (a) the double octahedral chain that forms the basic building unit for the } \\
\text { structures of these materials; (b) the } \mathrm{M}_{2} \mathrm{~S}_{5} \text { slab formed from linkage of } \\
\text { double octahedral chains; (c) } \mathrm{Er}_{2} \mathrm{CrS}_{4} \text { viewed along the [010] direction; } \\
\text { (d) the structure of } \mathrm{Er}_{4} \mathrm{CrS}_{7} \text { viewed along the [010] direction; (e) } \mathrm{Er}_{6} \mathrm{Cr}_{2} \mathrm{~S}_{11} \\
\text { viewed along the [100] direction. Non-framework erbium cations are } \\
\text { coloured magenta. Cyan- and magenta-coloured octahedra within the } \\
\text { cation-ordered framework of } \mathrm{Er}_{2} \mathrm{CrS}_{4} \text { denote centred with chromium and }\end{array}$ \\
\hline
\end{tabular}




\begin{tabular}{|c|c|}
\hline & $\begin{array}{l}\text { erbium respectively, whilst blue octahedra denote a disordered array of } \\
\text { erbium and chromium cations in the framework of } \mathrm{Er}_{4} \mathrm{CrS}_{7} \text { and } \mathrm{Er}_{6} \mathrm{Cr}_{2} \mathrm{~S}_{11} \text {. }\end{array}$ \\
\hline Figure 7 & $\begin{array}{l}\text { Powder neutron diffraction data collected for } \mathrm{Er}_{6} \mathrm{Cr}_{2} \mathrm{~S}_{11} \text { at } 4 \mathrm{~K}, 8 \mathrm{~K} \text {, and } \\
14 \mathrm{~K} \text {, illustrating the disappearance of weak reflections at } 3.14 \text { and } 3.17 \AA \\
\text { on heating through the temperature at which the maximum in the magnetic } \\
\text { susceptibility is observed }(11.4 \mathrm{~K}) \text { following subtraction of the } \\
\text { contribution due to } \mathrm{Er}^{3+} \text {. }\end{array}$ \\
\hline Figure 8 & $\begin{array}{l}\text { The magnetic exchange pathway due to } \mathrm{Er}^{3+} / \mathrm{Cr}^{2+} \text { ordering in the } \\
\text { octahedral framework of } \mathrm{Er}_{2} \mathrm{CrS}_{4} \text {. Small solid circles represent } \mathrm{Cr}(5) \text {, } \\
\text { small open circles } \mathrm{Cr}(6) \text { and large open circles sulphur. Erbium cations are } \\
\text { omitted. Short and long } \mathrm{Cr}-\mathrm{S} \text { distances are indicated respectively by filled } \\
\text { and unfilled bonds. }\end{array}$ \\
\hline
\end{tabular}


Figure 1

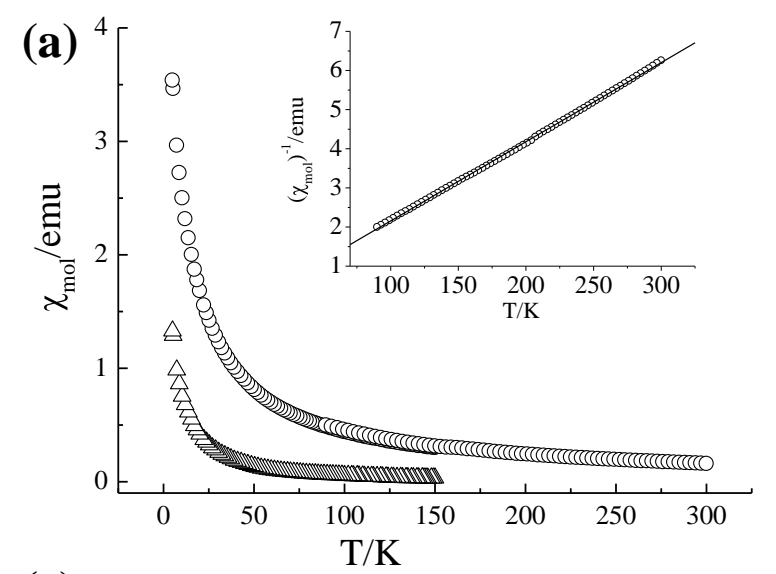

(c)

(b)

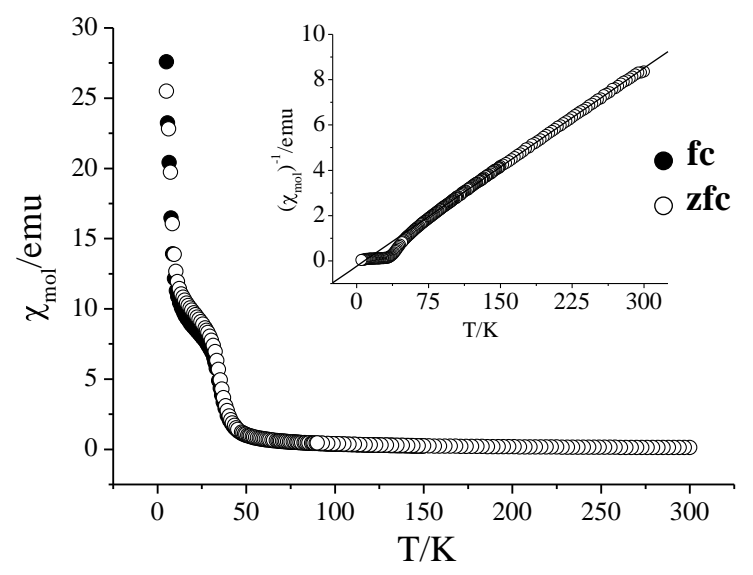

(d)
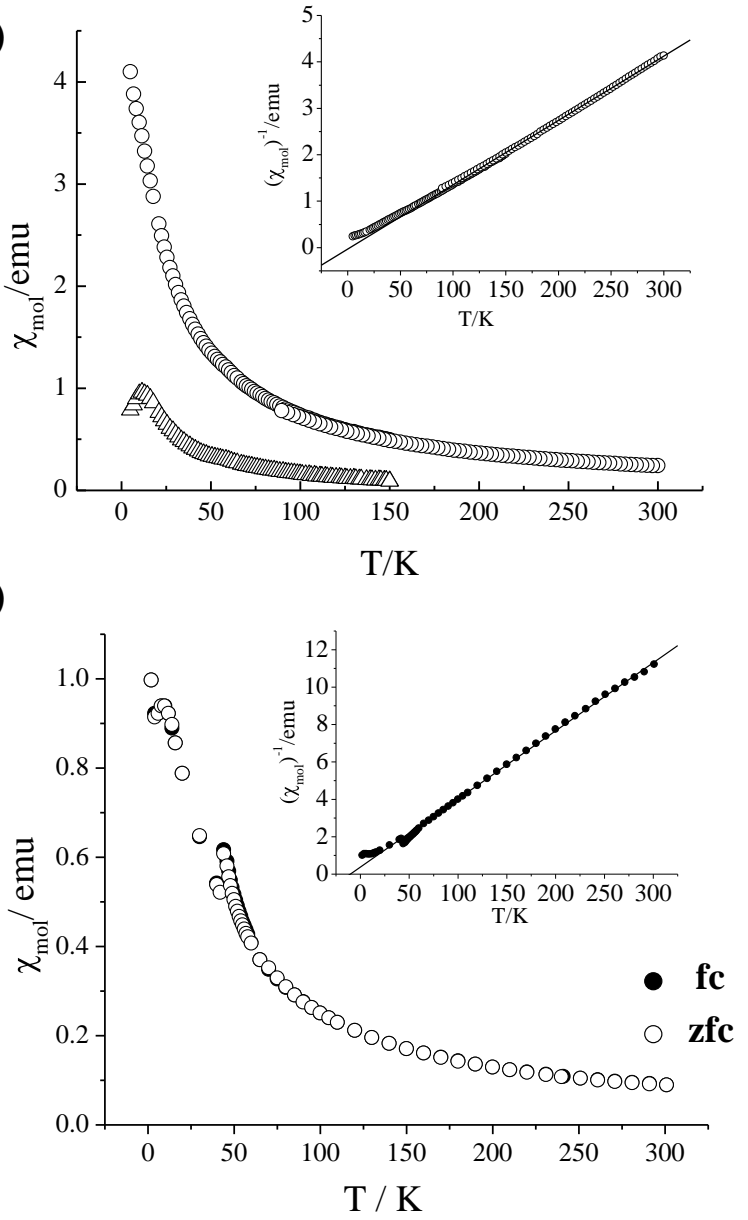
Figure 2

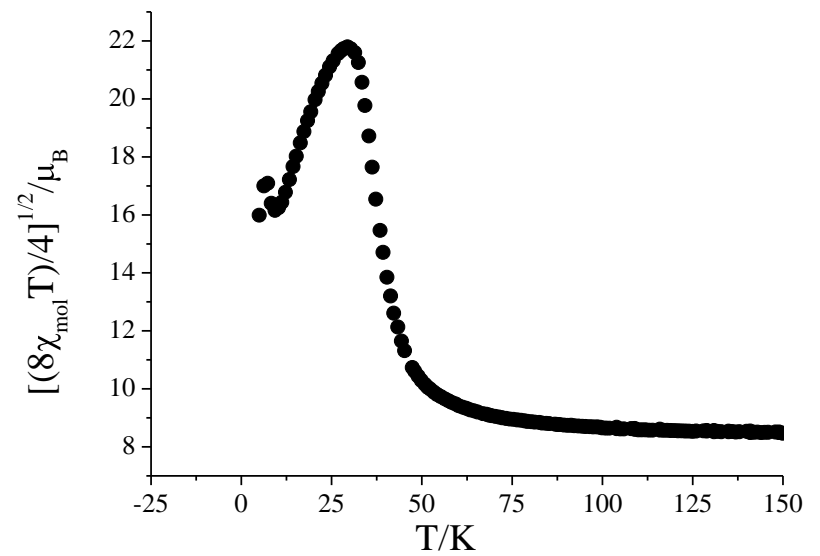


Figure 3

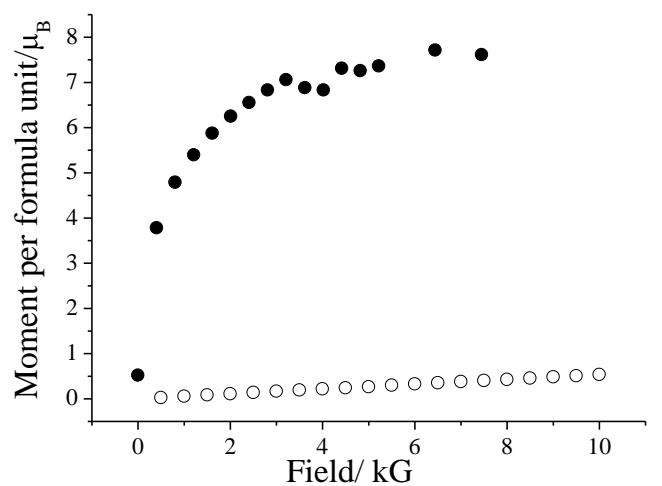


Figure 4

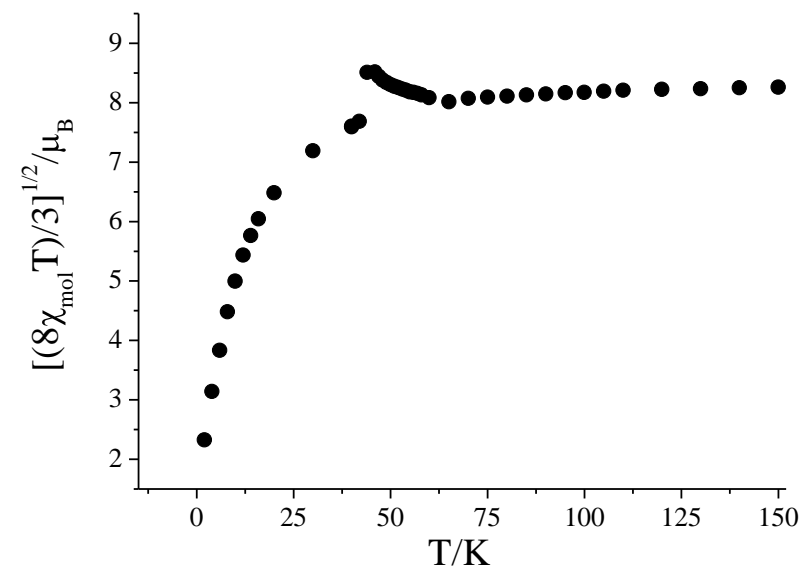


Figure 5

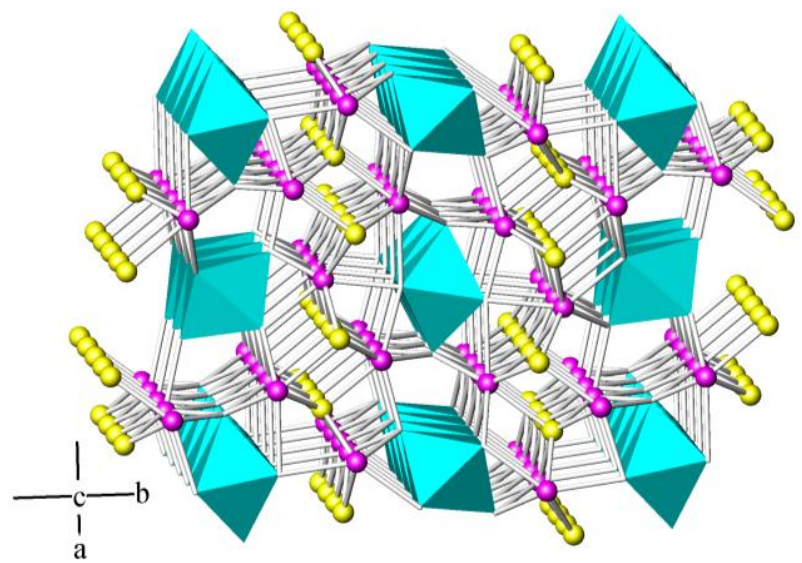


Figure 6

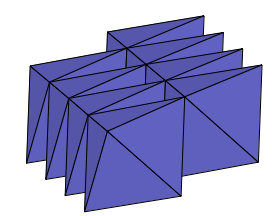

(a)

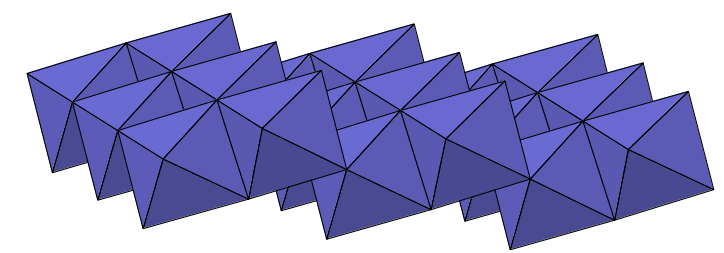

(b)

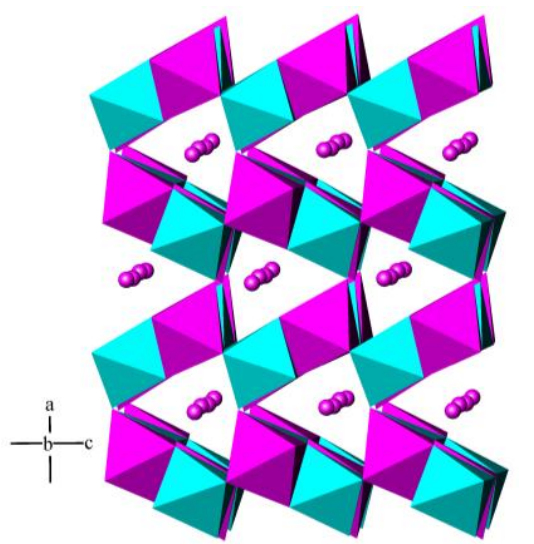

(c)

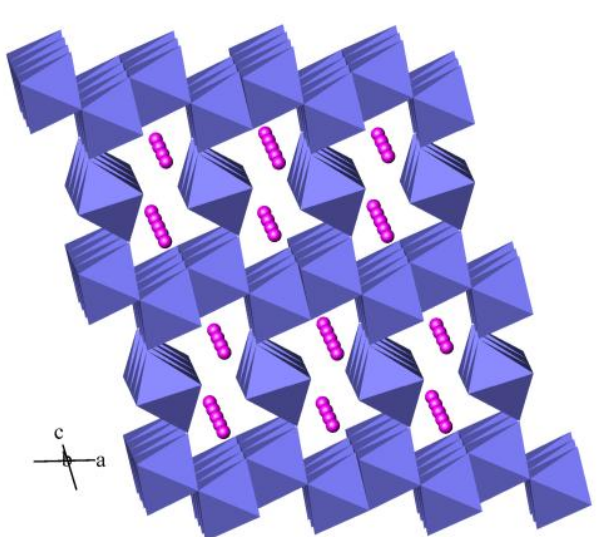

(d)

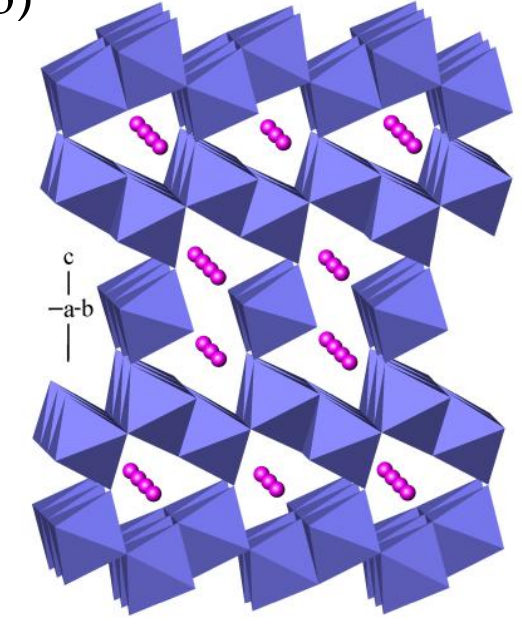

(e) 
Figure 7

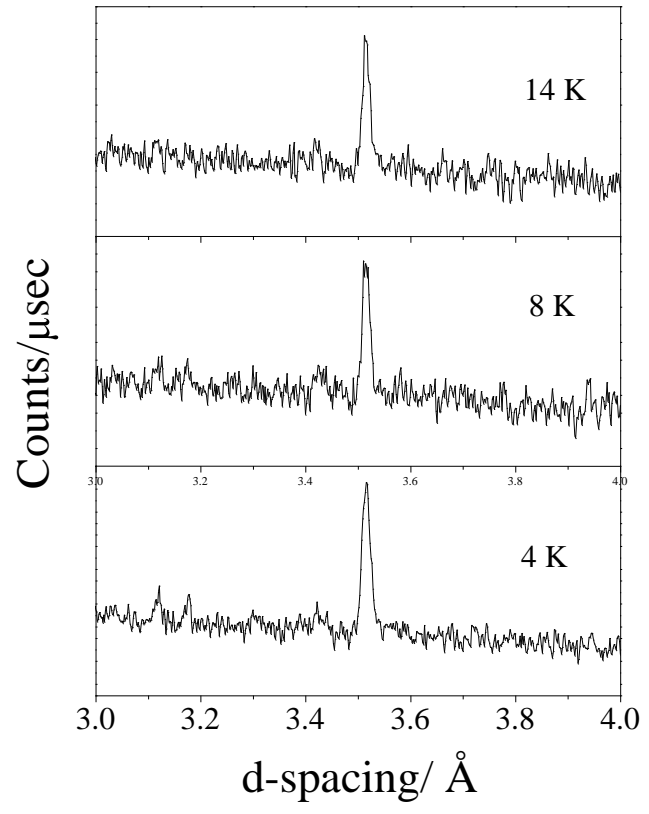


Figure 8

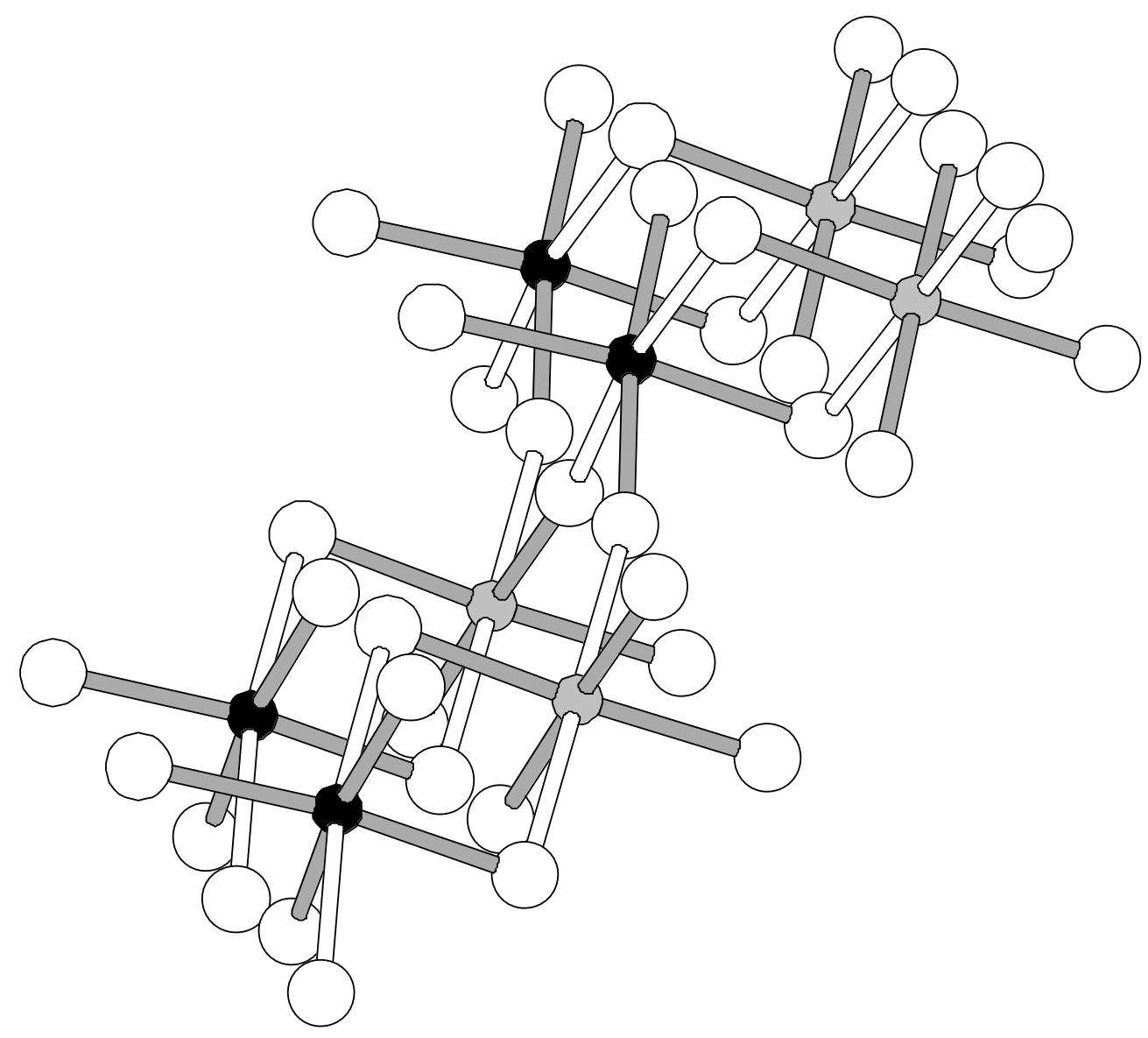




\section{Table of Contents Synopsis}

Linkage of $\mathrm{M}_{2} \mathrm{~S}_{5}$ slabs of varying thickness produces the octahedral frameworks of $\mathrm{Er}_{2} \mathrm{CrS}_{4}, \mathrm{Er}_{6} \mathrm{Cr}_{2} \mathrm{~S}_{11}$ and $\mathrm{Er}_{4} \mathrm{CrS}_{7}$ : the $\mathrm{n}=1,2$ and $\infty$ members of a series whose anionic framework is described by the general formula $\left[\mathrm{M}_{2 \mathrm{n}+1} \mathrm{~S}_{4 \mathrm{n}+3}\right]^{\mathrm{x}-}$. The presence of longrange magnetic order may be related to the degree of $\mathrm{Er} / \mathrm{Cr}$ ordering.

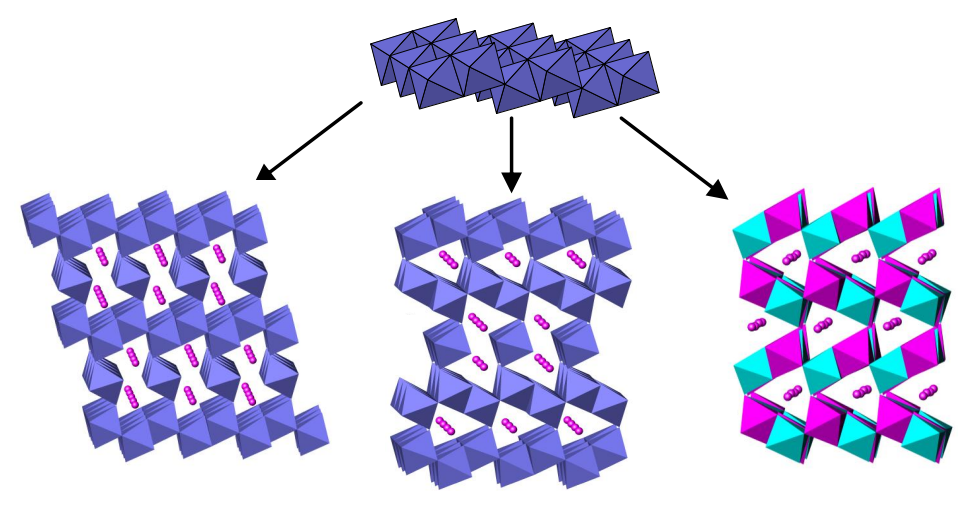

